
\title{
25 Research Square \\ Quality of care is Myth or Reality? A study of PHCs in Maharashtra
}

\section{Kadam Sanjay Ramrao}

Sree Chitra Tirunal Institute for Medical Sciences and Technology

Srinivasan Kannan ( $\nabla$ kannansrini@ymail.com )

Sree Chitra Tirunal Institute for Medical Sciences and Technology https://orcid.org/0000-0003-27319428

\section{Research Article}

Keywords: Access, Healthcare delivery, Healthcare Quality, Health services needs and demand, Professional-Patient relations, Process assessment

Posted Date: September 28th, 2021

DOI: https://doi.org/10.21203/rs.3.rs-944328/v1

License: (9) This work is licensed under a Creative Commons Attribution 4.0 International License. Read Full License 


\section{Abstract}

\section{Background:}

Maharashtra State Quality Assurance Program was evolved and pilot project was launched in 2006-07. In 2011 as Phase three it was launched in Beed district.

\section{Objectives:}

Objectives of the present study are to assess client's perception on quality and satisfaction of healthcare at PHCs and their correlates and job satisfaction among health personnel.

\section{Methods:}

Cross sectional study was conducted among randomly selected 20 PHCs from Beed district.

Data collected from 400 new clients of outpatient department of PHCs. From clients, demographics, socioeconomic status, perception on quality of outpatient care and their satisfaction were collected using structured questionnaire. From the health personnel data on socio-demographic details, and job satisfaction were collected. Univariate, bivariate, and multivariate analyses were performed.

\section{Results:}

In total $50 \%$ of clients perceived better quality and $53 \%$ of them were satisfied with the services of PHCs. The factors found to be significantly associated with perception of better quality of services and client satisfaction were sex, education, occupation, perception on provider's attitude, examination time and opted due to financial reasons. About $57 \%$ health personnel satisfied with job. All dissatisfied were medical officers.

\section{Conclusion:}

The study found only around half of them is satisfied with services. Findings suggest infrastructure and drug alone will not improve the satisfaction, but the state need to improve the human aspects of services with more interaction and thorough examination of the clients. To improve services working conditions will have to be improved for health personnel.

\section{Key Message}

Quality of health services is not just about infrastructure and drug availability but one also need to improve the human aspects of services. In addition it is important to improve working conditions of the health personnel.

\section{Introduction}


Quality Assurance Program in Maharashtra was evolved during 2006-07 and launched phased manner in different districts. During 2011-2012. in Phase III it was launched in Beed district. The present study was conducted during 2014 and completed before the Government of India guidelines issued for implementation of Quality Assurance Program in November 2014. ${ }^{1}$ The present paper is an assessment of client's perception in terms of satisfaction and service utilization in Primary Health centres in Beed district, Maharashtra.

\section{Quality of Care}

Utilization of health services depend on the quality of services delivered. Improving the quality of healthcare provision is advocated as an answer to better health outcomes for all. ${ }^{2}$ Quality is a measurement of health services for improving health outcome of individuals and population, that is related to current professional knowledge and expectations of cleints. ${ }^{3}$ Improving and sustaining healthcare in hospital setting continue to challenge practitioners and policy makers. ${ }^{4}$ There are multiple definitions of quality of care and they are different for providers and users. ${ }^{4}$ Quality of care neither be viewed from the providers' perspective nor from users' perspective. Their distinction of quality is in terms of observed and perceived quality. ${ }^{5}$ According to Donabedian, quality of care assessment is done by studying structure, process and outcome in a system. ${ }^{6}$ According to him, the three are influencing one another to achieve quality in a health setting. For instance, good structure improves likelihood of good process that in turn increases likelihood of good outcome. ${ }^{7}$ World Health Organization (WHO) suggests that a health system should seek to make improvements in six areas of quality viz. effective, efficient, accessible, acceptable, and equitable and safe. ${ }^{8}$ WHO is working with different countries by promoting interventions to develop policies and strategies to strengthen and improve health care systems to deliver cost effective and sustainable quality of services. ${ }^{9,10}$

\section{Quality Assurance in healthcare}

Quality assurance program is one of the initiatives from WHO to improve quality of health care. India is increasingly pursuing for utilization of health care through National Health Mission to achieve Universal Health Coverage. ${ }^{11}$ In 2007 National Rural Health Mission (NRHM) of the Ministry of Health and Family Welfare (MOHFW), Population Council, and United Nations Population Fund (UNFPA) jointly introduced a quality assurance (QA) program for assessing and improving of the quality of services at public health facilities. ${ }^{12}$ Seven years since the initiation of the quality assurance program, little information is available on the quality of primary health care in Maharashtra state in India. Assessment of quality and maintaining quality of primary health care is a continuous process. ${ }^{13}$ Measurement of primary health care performance and introduction of new performance indicators are major issues in quality. ${ }^{14}$ Prevention, quality of life and satisfaction with health services are important indicators of care for healthy population. ${ }^{15}$ Client's perception of quality of health care is critical to understand the relationship between quality of care and utilization of health services, and increasingly treated as an outcome of health care delivery. ${ }^{16,17}$ Client's views are being given more importance in policy making. To understand 
population's perception on quality of care, it is critical to develop measures related to utilization of primary health care services. ${ }^{16}$ People's perception about quality of care often determines health seeking and continuous use of services. ${ }^{18}$ The efficacy of health care is enhanced by greater client satisfaction. Client satisfaction is undoubtedly a useful measure, that is based on client's accurate assessment and acts as a direct indicator of quality care. ${ }^{19}$ There are very few studies that documented quality of primary health care in Maharashtra. When we reviewed we did not come across any study that covers all three dimensions of quality specifically structure, process and outcome in Maharashtra. There was no study conducted in Beed district.

Objectives of this paper are to assess client's perception about quality of primary health centre and their satisfaction about services provided at primary health centres in Beed district and to find correlates of client satisfaction and perception about quality of primary health centre.

\section{Materials And Methods}

\section{Ethics}

Ethical clearance was obtained from the Technical Advisory Committee and Institutional Ethics Committee (SCT/IEC/602/JUNE-2014) of SCTIMST after fulfilling all the criteria of informed consent, development of study tool and how to manage the study within specified time period.

\section{Study design}

For the present study we have used cross sectional design. Data were collected from Beed district of Maharashtra, India. For the study the primary level institutions namely Primary health centres were included. The respondents were the new clients who sought care at outpatient department (OPD) at primary health centre $(\mathrm{PHC})$ and health personnel working in primary health centre. Assuming $60 \%$ prevalence of workload with $70 \%$ Confidence Interval within $\pm 5 \%$, the required minimum sample size was estimated to be 323 and it was rounded to 400 keeping the 20 percent non response rate in mind. For the present study the sample size was estimated using Openepi software version 3.01. Randomly $20 \mathrm{PHCs}$ were selected for the study. From each PHC, data was collected from 20 clients each. From each PHC, 10 male and 10 female clients of age 18 years and above and 60 years and below who visited OPD were selected randomly for exit interview. All clients who were seeking care and whose age above 18 years and below 60 years were included and those who attended OPD but not residents of Beed District, terminally ill and who were not consenting to participate were excluded from the study.

For clients, quality of perception and satisfaction, the tool used for data collection was structured questionnaire based on scale developed by Rao et al in $2003 .{ }^{20}$ This scale was translated to Marathi by principle investigator and back translated to Hindi by another person who was familiar with both languages. Back translated scale accuracy was 94 percent. It was matching the original scale so it was validated to use the scale. For socio demographic information indicators used in NFHS-3 to measure 
standards of living index (SLI index) were adopted. ${ }^{21}$ The data collection was done from June 16th to July 23rd 2014 by the principal investigator. The permission from the Director of Health Services was obtained. List of 50 PHCs was obtained from District Health office and it was arranged in alphabetical order and 20 random PHCs are selected by using Graph pad software version 6. From each PHC 20 clients (10 male and 10 female) who were seeking care at OPD were selected for data collection. Response rate was 87.72 percent.

Five health personnel from the same PHC were selected and data for job satisfaction was collected from respective health personnel. At some places if posts of concerned designation were vacant then data was not collected. Thus expected data for job satisfaction of health personnel was 100 but we could collect data from 93 health persons. In 20 PHCs we found 7 posts of expected health personnel were vacant.

\section{Study variables}

Quality of Primary health centre can be defined as the best structure, process and outcome with preference to Client care. Structure and process indicators were taken as predictor variables and client's satisfaction and perception about quality were taken as outcome variable to assess quality of Primary health care. The specific variables include, client satisfaction seeking care at OPD in PHC, perception about quality of services given at OPD in PHC, socio demographic characteristics such as, age, sex, marital status, education, occupation, social status and accessibility of primary health centre, satisfaction with quality of services variables including, time spent for registration, waiting time after registration, examination time, perception on doctor's expertise, perception on doctor's attitude, investigations advised, reasons for opting PHC.

For health professionals, job satisfaction, socio-demographic details, designation, years of experience, duration of service in present post and whether staying in vicinity of PHC or not, pay, promotion, supervision, fringe benefits, contingent rewards, operating conditions, co-workers, nature of work and communication of the health professionals were collected.

Operationalization of variables

1. Perceived better quality of services (PBQS)-Mean sore was taken as level of perception about quality of services and it was taken as a cut of point to decide perceived better quality of services. Respondents who were having score more than mean score were considered that they had perceived better quality of services.

2. Client satisfaction (CS)-Mean score was taken as level of satisfaction and it was taken as a cut of point to decide client satisfaction. Respondents who were having score more than mean score satisfied with quality of services.

3. Job satisfaction - Job Satisfaction Survey, developed by Paul E. Spector(1994) ${ }^{39}$ an open access scale for non commercial and academic purpose and generalized in India by Pradnya Takalkar et al in $1994 .{ }^{40}$ 
For job satisfaction we used 36 items scale in which there were total 9 subscales on pay, promotion, supervision, fringe benefits, contingent rewards, operating conditions co-workers, nature of work and communication.

\section{Statistics}

Univariate analysis was done first. Then independent variables were categorised in suitable categories and bivariate analysis was performed on those variables using chi square test for outcome variables client's satisfaction and perceived quality of services. Significant variables and near to significant were considered for multivariate analysis. Multivariate analysis was done by using Binary logistic regression using backward LR model.IBM SPSS version 21 was used for data analysis.

Institutional Review Board Approval (or discussion of waiver)

\section{Results}

\section{Client satisfaction and their perception about quality of services}

Total 400 clients attending outpatient care were interviewed for perception about quality and their satisfaction about services provided and 93 health personnel were interviewed on job satisfaction. In first part client satisfaction and their perceived quality are discussed. Respondent characteristics are presented in Table 1.

\section{Table 1 Here}

Mean family size of the house hold was $5.71( \pm 2.43)$. Of these family members mean earning members were 2.18 ( \pm 1.23$)$. The mean SLI score was 15.18 ( \pm 5.04$)$. Among the respondents, 40 percent belong to low socioeconomic status(SES), 52.8 percent belong to medium SES and 7.2 percent to high SES. About 42 percent of clients opting for $\mathrm{PHC}$ services due to various financial reasons.

\section{Table 2 Here}

Mean score for client satisfaction was 3.26( \pm 0.72$)$. There were 53.8 percent of clients satisfied with services provided by PHC (Refer Table 2). Table 2 shows the Mean score for PBQS was $3.03( \pm 0.61)$ and 50.1 percent of clients perceived quality of services are better. Table 2 also shows, clients had better perception on clinic infrastructure, and availability of medicines. They had poor perception about the medical information, doctor behaviour and staff behaviour. Quality perception viewed in terms of structure, process and outcome.The indicators related to structure are having better performance than process.

\section{Table 3 Here}

Table 4 Here 


\section{Patient satisfaction a Bivariate Analysis}

For bivariate analysis we classified independent variables in suitable categories and then chi-square test was done. Where chi-square test can't be performed, we applied one-way Anova for further analysis. This was helpful in identifying factors associated with patient satisfaction. In Table 3 significantly associated variables are presented. The factors shown in table have significant association with patient satisfaction. Perceived patient satisfaction associated significantly with age, sex, education and occupation of the respondents. It was also associated with their perceptions on waiting time after registration, time spent by doctor for examination, perceptions on doctor's expertise, doctor's attitude and reason for opting PHC.

\section{Bivariate analysis of perceived quality}

This was done as mentioned above for independent variables by applying Chi-square test and one-way Anova test and results are obtained. Only significant findings are presented in Table-4. Except for waiting time after registration, all factors that are significantly associated with Patients' Satisfaction are also significantly associated with perceived quality of services.

\section{Table 5 Here}

The factors significantly associated with client satisfaction and PBQS based on multivariate analysis are presented in Table 5. Client satisfaction changes significantly with change in socio-demographic factors such as sex and occupation of client. The significant factors related to their perceptions about experience in OPD were examination time, and reason for opting PHC. Perceived quality changes significantly with change in socio-demographic factors such as sex, and education of client (Please refer Table 6). The significant factors related to their perceptions about experience in OPD were examination time and perceptions on doctor's attitude.

\section{Table 6 Here}

\section{Job satisfaction}

The mean scores for total satisfaction of health personnel is $148.35( \pm 25.1)$ and their subscale values ranges from 10.7 to 21.5 . Mean scores for pay(16.11 \pm 5.38$)$, promotion(12.88 \pm 5$)$, supervision(20.35 \pm $4.04)$, fringe benefits(14.14 \pm 4.7$)$, contingent rewards(14.04 \pm 5.04$)$, operating conditions $(10.7 \pm 3.33)$, co workers(19.9 \pm 4.3$)$, nature of work(21.5 \pm 2.8$)$ and communication(18.7 \pm 4.96$)$. Mean values explain that health personnel are dissatisfied with Operating conditions and there are ambivalent results for pay, promotion, fringe benefits and contingent rewards. The results also show they are satisfied with supervision, co workers, nature of work and communication.

The job satisfaction of health workers are described for total satisfaction and satisfaction according to sub scale. The Total Satisfaction score for Satisfied, Ambivalent and Dissatisfied are $53(57 \%), 36$ (38.7\%), and 4 (4.3\%) respectively. Four factors in which personnel satisfied include, supervision (84.9\%), co-workers(77.4\%), nature of work(92.5\%) and communication(72\%). They are the contributing factors for 
total satisfaction. Five factors in which personnel dissatisfied include, operating conditions (71\%), pay $(20.4 \%)$, promotion (44.1\%), fringe benefits (35.5\%) and contingent rewards $(38.7 \%)$. These were the deducting factors for total satisfaction. The respondents were more satisfied with nature of work, co workers, supervision and communication as compared to other domains.

\section{Discussion}

As discussed earlier 50.1 percent clients perceived better quality of services (PBQS) and 53.8 percent clients were satisfied with the PHC services. Findings in our study are similar to previous studies conducted among different population groups in India. ${ }^{20,22,23,24,25}$ Our findings are contradictory to the studies from India. ${ }^{26,27}$ Men perceived better quality of services than women in our study. It may be due to lack of privacy in outpatient departments of PHCs. Women were uncomfortable to consult male with doctors and women had fewer choices due to financial reasons. Literate clients perceived better quality of services than illiterate clients. This may be due to difference in understanding and expectations of the services. The expectations of illiterate clients from primary health centres are very high. They are expecting even advanced curative services such as, advanced radiological investigations and specialist services at the PHC level. Education level of clients improves their understanding about the services provided in PHCs. This finding is in confirmation with earlier studies. ${ }^{28,29}$ Daily wagers were less satisfied than others. This is also related with the financial reasons for opting PHC services. The service related factors associated with client satisfaction were examination time and reasons for opting services. Those who spent more time in examination were highly satisfied. This is an important factor associated with client satisfaction and in confirmation with earlier studies conducted in India and abroad. 30,31,32,33,34 Examination time plays a crucial role among clients and it suggests that doctor have examined clients properly, explained them about diagnosis and treatment which ultimately leads to client satisfaction. This finding is in confirmation with the findings of earlier study and suggests that client satisfaction is explained by client interaction with health personnel and not health facility characteristics such as infrastructure, availability of medicines and cleanliness of health facility. ${ }^{35}$ Clients who had opted services due to financial reasons are less satisfied compared to those who opted services due to non financial reasons. This is a is new finding of our study. We found that the clients of our study area were satisfied with availability of medicines and clinic infrastructure better than doctor behavior, staff behavior and medical information. This finding is in contradiction to earlier study findings. ${ }^{36}$ Large investments in infrastructure development and medicine purchases through NRHM resulted in better satisfaction in these domains of quality. Our findings are in confirmation with findings of earlier study conducted in Satara district of Maharashtra. ${ }^{26}$ These are structural indicators of our conceptual framework which contributing to client satisfaction. On the other hand process indicators such as staff behavior, doctor behavior and medical information are curtailing client satisfaction in our study. These factors are closely related with burden of workload on health personnel and their job satisfaction. ${ }^{37,38}$

In our study we found that 57 percent health personnel were satisfied with their job and 38.7 percent were ambivalent with their job. Only 4.3 percent health personnel were dissatisfied with their job. All these 
dissatisfied health personnel were Medical officers. Our findings are in confirmation with earlier studies. ${ }^{41,42,43,44}$ In our study we found one correlate significantly associated with job satisfaction and it was designation of health personnel. We found that MPW (male) and MPW (female) are more satisfied than Medical officers and pharmacists working in PHC. There were 71.8 percent MPW (female) and 78.9 percent MPW (male) satisfied with their job as compared to 20 percent Medical officers and 40 percent pharmacists. This may be due their qualification as compared to Medical officers and pharmacist. Medical officers and pharmacists had to spent minimum 5-7 years after matriculation to achieve minimum qualification and what they get is not sufficient after spending more years in education as compared to MPW (male) and MPW (female) who spent one or one and half year after matriculation to achieve minimum qualification for their post. We found in our study that health personnel were satisfied with nature of work, supervision, co workers and communication while dissatisfied with pay, promotion, fringe benefits, contingent rewards and operating conditions. This clearly indicates that health personnel were maintaining their work environment healthy but there was least support from higher authorities in form of pay and promotion.

Quality of care in health sector is an important subject needs more investigation. Present study assessed the quality of Primary health care by studying the client satisfaction on services. This study found only around half of them are satisfied against the general belief which is higher than this. Many of the times the policy makers think creation of infrastructure and provide drugs will improve client satisfaction. Findings of our study suggest infrastructure and drug alone will not improve the satisfaction or the perceived quality of services. The respondents felt the need for improvement in the human aspects of services. Client feel satisfied if the service provider interact with them properly and examine them thoroughly. We should not follow only on tangible things such as infrastructure and medicines but also on human aspects. There is a need to put more efforts to improve doctor client interaction. This necessitates improvements in the attitude of health professional. In addition to the socio demographic factors, examination time, attitude of doctors are contributing to satisfaction. The daily wagers and women those who opted for PHC services because of their financial constraints expressed poor satisfaction. In case they had money they would have moved to other institutions. This shows the poor state of affairs of the PHCs. Government being the major service provider should be a role model to others. But in reality it ignored the human aspects of service provision by focusing only on infrastructure and medicine. It is high time to give importance to both human and material aspects.

\section{Recommendations}

There is an urgent need to improve interaction between client and health personnel. This can be achieved only providing training to health personnel.

\section{Declarations}

Declaration of Conflicting Interests 
The Authors declare that there is no conflict of interest.

\section{References}

1. Maharashtra State Quality Assurance Program Short Note. National Health Mission, Maharashtra. https://arogya.maharashtra.gov.in/Site/Uploads/Category/QAShortNote.pdf Accessed on 9th July 2015.

2. Roy MP, Mohan U, Singh SK, Singh VK, Srivastava AK. Factors associated with the preference for delivery at the government hospitals in rural areas of Lucknow district in Uttar Pradesh. Indian J Public Health 2013; 57: 268-71.

3. Cohn KH, Hough DE. The Business of Healthcare: Improving systems of care. Greenwood Publishing Group, 2008.

4. Beattie M, Lauder W, Atherton I, Murphy DJ. Instruments to measure patient experience of health care quality in hospitals: a systematic review protocol. Syst Rev 2014; 3 :

5. Karkee R, Lee AH, Pokharel PK. Women's perception of quality of maternity services: a longitudinal survey in Nepal. BMC Pregnancy Childbirth 2014; 14: 45.

6. Bergman B, Neuhauser D, Provost L. Five main processes in healthcare: a citizen perspective. BMJ Qual Saf 2011; 20: i41-i42.

7. Donabedian A. The quality of care: How can it be assessed? JAMA 1988; 260: 1743-

8. Quality of care: a process for making strategic choices in health systems. Geneva: World Health Organization, 2006 http://www.who.int/management/quality/assurance/QualityCare_B.Def.pdf.

9. WHO | MDG 5: improve maternal health. WHO.

http://www.who.int/topics/millennium_development_goals/maternal_health/en/ (accessed March 9, 2014).

10. WHO I MDG 6: combat HIV/AIDS, malaria and other diseases. WHO. http://www.who.int/topics/millennium_development_goals/diseases/en/ (accessed March 9, 2014).

11. Duran A, Kutzin J, Menabde N. Universal coverage challenges require health system approaches; the case of India. Health Policy 2014; 114: 269-77.

12. Dodwad SS. Quality management in healthcare. Indian J Public Health 2013; 57: 138-43.

13. Roemer MI, Montoya-Aguilar C, Organization WH. Quality assessment and assurance in primary health care / M. I. Roemer and C. Montoya-Aguilar. 1988. http://apps.who.int/iris/handle/10665/40663 (accessed Feb 22, 2014). 
14. Jurgutis A, Vainiomäki P, Stašys R. Primary health care quality indicators for a more.sustainable health care system in Lithuania. http://vadyba.asu.It/26/76.pdf.

15. Mainz J. Defining and classifying clinical indicators for quality improvement. Int J Qual Health Care 2003; 15: 523-30.

16. Baltussen R, Yé Y, Haddad S, Sauerborn RS. Perceived quality of care of primary health care services in Burkina Faso. Health Policy Plan 2002; 17: 42-8.

17. Johansson P, Oléni M, Fridlund B. Patient satisfaction with nursing care in the context of health care: a literature study. Scand J Caring Sci 2002; 16: 337-44.

18. Haldar D, Sarkar A, Bisoi S, Mondal P. Assessment of Client's Perception in Terms of Satisfaction and Service Utilization in the Central Government Health Scheme Dispensary at Kolkata. Indian J Community Med Off Publ Indian Assoc Prev Soc Med 2008; 33: 121-3.

19. Aldana JM, Piechulek H, Al-Sabir A. Client satisfaction and quality of health care in rural Bangladesh. Bull World Health Organ 2001; 79: 512-7.

20. Rao KD, Peters DH, Bandeen-Roche K. Towards patient-centered health services in India-a scale to measure patient perceptions of quality. Int J Qual Health Care 2006; 18: 414-21.

21. Bhanderi MN, Kannan S. Untreated reproductive morbidities among ever married women of slums of Rajkot City, Gujarat: the role of class, distance, provider attitudes, and perceived quality of care. J Urban Health Bull N Y Acad Med 2010; 87: 254-63.

22. Chandwani H, Jivarajani P, Jivarajani H. Community Perception And Client Satisfaction About The Primary Health Care Services In A Tribal Setting Of Gujarat - India. Internet J Health; .2008 Volume 9 Number 2. http://ispub.com/IJH/9/2/8795.

23. Patro BK, Kumar R, Goswami A, Nongkynrih B, Pandav CS, UG Study Group. Community Perception and Client Satisfaction about the Primary Health Care Services in an Urban Resettlement Colony of New Delhi. Indian J Community Med Off Publ Indian Assoc Prev Soc Med 2008; 33: 250-4.

24. Ray SK, Basu SS, Basu AK. An assessment of rural health care delivery system in some areas of West Bengal-an overview. Indian J Public Health 2011; 55: 70-80.

25. Griffiths P, Stephenson R. UNDERSTANDING USERS' PERSPECTIVES OF BARRIERS TO MATERNAL HEALTH CARE USE IN MAHARASHTRA, INDIA. J Biosoc Sci 2001; 33: 339-59.

26. Vlassoff C, Tanner M, Weiss M, Rao S. Putting people first: a primary health care success in rural India. Indian J Community Med Off Publ Indian Assoc Prev Soc Med 2010; 35: 326-30. 
27. Holikatti PC, Kar N, Mishra A, Shukla R, Swain SP, Kar S. A study on patient satisfaction with psychiatric services. Indian J Psychiatry 2012; 54: 327-32.

28. Singh H, Haqq ED, Mustapha N. Patients' perception and satisfaction with health care professionals at primary care facilities in Trinidad and Tobago. Bull World Health Organ 1999; 77: 356-60.

29. Birhanu Z, Assefa T, Woldie M, Morankar S. Determinants of satisfaction with health care provider interactions at health centres in central Ethiopia: a cross sectional study. BMC Health Serv Res 2010; 10: 78.

30. Bakshi SMH. A study of patient satisfaction at a tertiary care hospital in Hyderabad, India. World Hosp Health Serv Off J Int Hosp Fed 2013; 49: 26-9.

31. Shendurnikar N, Thakkar PA. Communication skills to ensure patient satisfaction. Indian J Pediatr 2013; 80: 938-43.

32. Shi L, Lebrun-Harris LA, Daly CA, et al. Reducing disparities in access to primary care and patient satisfaction with care: the role of health centers. $J$ Health Care Poor Underserved 2013; 24: 56-66.

33. Fitzpatrick R. Capturing what matters to patients when they evaluate their hospital care. Qual Saf Health Care 2002; 11: 306-306.

34. Burnham G, Hoe $C$, Hung $Y$, et al. Perceptions and utilization of primary health care services in Iraq: findings from a national household survey. BMC Int Health Hum Rights 2011; 11: 15.

35. Hansen PM, Peters DH, Viswanathan K, Rao KD, Mashkoor A, Burnham G. Client perceptions of the quality of primary care services in Afghanistan. Int J Qual Health Care 2008; 20: 384-91.

36. AL-Ahmadi H, Roland M. Quality of primary health care in Saudi Arabia: a comprehensive review. Int J Qual Health Care 2005; 17: 331-46.

37. Goetz K, Campbell SM, Steinhaeuser J, Broge B, Willms S, Szecsenyi J. Evaluation of job satisfaction of practice staff and general practitioners: an exploratory study. BMC Fam Pract 2011; 12: 137.

38. Cockcroft A, Milne D, Oelofsen M, Karim E, Andersson N. Health services reform in Bangladesh: hearing the views of health workers and their professional bodies. BMC Health Serv Res 2011; 11 Suppl 2: S8.

39. Spector PE. Measurement of Human service staff satisfaction: Development of job satisfaction survey. Am J Community Psychol 1985;13:693-713.

40. Takalkar P, Coovert MD. International Replication Note The Dimensionality of Job Satisfaction in India. App/Psychol 1994;43:415-26. 
41. Kaarna M, Põlluste K, Lepnurm R, Thetloff M. The progress of reforms: job satisfaction in a typical hospital in Estonia. Int J Qual Health Care 2004;16:253-61.

42. Lu H, While AE, Barriball KL. Job satisfaction and its related factors: a questionnaire survey of hospital nurses in Mainland China. Int J Nurs Stud 2007;44:574-88.

43. Goetz K, Campbell SM, Steinhaeuser J, Broge B, Willms S, Szecsenyi J. Evaluation of job satisfaction of practice staff and general practitioners: an exploratory study. BMC FamPract 2011;12:137.

44. Cockcroft A, Milne D, Oelofsen M, Karim E, Andersson N. Health services reform in Bangladesh: hearing the views of health workers and their professional bodies. BMC Health Serv Res 2011;11Suppl 2:S8.

\section{Tables}

Table 1 Respondent characteristics of study sample $(\mathrm{N}=400)$ 


\begin{tabular}{|c|c|}
\hline Respondents Characteristics & $\mathrm{N}(\%)$ \\
\hline Mean Age & $37.08 \pm 13.19 @$ \\
\hline Sex-Male & $196(49)$ \\
\hline Female & $204(51)$ \\
\hline \multicolumn{2}{|l|}{ Marital Status } \\
\hline \multirow{2}{*}{$\begin{array}{l}\text { 1. Currently married } \\
\text { 2. Unmarried }\end{array}$} & $332(83)$ \\
\hline & $68(17)$ \\
\hline \multicolumn{2}{|l|}{ Education } \\
\hline \multirow{5}{*}{$\begin{array}{l}\text { 1. Not able to read or write } \\
\text { 2. Able to read and write } \\
\text { 3. Primary (1-7) } \\
\text { 4. Secondary (8-10) } \\
\text { 5. Higher Secondary and plus }\end{array}$} & $125(31.2)$ \\
\hline & $43(10.8)$ \\
\hline & $85(21.2)$ \\
\hline & $93(23.2)$ \\
\hline & $33(13.4)$ \\
\hline \multicolumn{2}{|l|}{ Occupation } \\
\hline \multirow{4}{*}{$\begin{array}{l}\text { 1. Own Business } \\
\text { 2. Daily Wagers } \\
\text { 3. House work } \\
\text { 4. Others }\end{array}$} & $145(36.2)$ \\
\hline & $159(39.8)$ \\
\hline & $56(14)$ \\
\hline & $40(10)$ \\
\hline \multicolumn{2}{|l|}{ Religion } \\
\hline \multirow{3}{*}{$\begin{array}{l}\text { 1. Hindu } \\
\text { 2. Muslim } \\
\text { 3. Buddhists }\end{array}$} & $309(77.2)$ \\
\hline & $52(13)$ \\
\hline & $39(9.8)$ \\
\hline \multicolumn{2}{|l|}{ Caste } \\
\hline \multirow{5}{*}{$\begin{array}{l}\text { 1. General } \\
\text { 2. Schedule Caste } \\
\text { 3. Schedule Tribe } \\
\text { 4. Other Backward Classes } \\
\text { 5. Don't know }\end{array}$} & $144(36)$ \\
\hline & $90(22.5)$ \\
\hline & $7(1.8)$ \\
\hline & $152(38.3)$ \\
\hline & $4(1)$ \\
\hline
\end{tabular}

@- Mean age and Standard deviation 
Table 2 Client satisfaction and perceived Quality

\begin{tabular}{|llll|}
\hline Outcome variable & Median & Mean \pm S.D & $N(\%)$ \\
\hline Client Satisfaction & 3.5 & $3.26 \pm 0.72$ & $215(53.8)(\mathrm{N}=400)$ \\
\hline Respondents who perceived better & & & \\
$\quad$ 1. Perceived Quality of services & 3.03 & $3.03 \pm 0.61$ & $196(50.1)(\mathrm{N}=391)$ \\
$\begin{array}{l}\text { 2. Availability of Medicines } \\
\text { 3. Medical information }\end{array}$ & 3.5 & $3.27 \pm 0.87$ & $230(57.5)(\mathrm{N}=400)$ \\
$\begin{array}{l}\text { 4. Staff behavior } \\
\text { 5. Doctor behavior }\end{array}$ & 2.67 & $2.69 \pm 0.98$ & $176(44.2)(\mathrm{N}=398)$ \\
6. Clinic infrastructure & 3.5 & $3.25 \pm 0.87$ & $206(51.5)(\mathrm{N}=400)$ \\
& 3.4 & $3.24 \pm 0.73$ & $201(50.6)(\mathrm{N}=397)$ \\
& 2.75 & $2.72 \pm 0.88$ & $234(59.2)(\mathrm{N}=295)$ \\
\hline
\end{tabular}


Table-3 Factors associated with Patient Satisfaction Bivariate Analysis

\begin{tabular}{|c|c|c|c|}
\hline \multirow[t]{4}{*}{ Respondent Characteristics } & Respondent's & Odds Ratio (95\% & P value \\
\hline & Satisfaction & C.I.) & \\
\hline & N (\%) & & \\
\hline & $(\mathrm{N}=\mathbf{2 1 5})$ & & \\
\hline
\end{tabular}

Age (In Years)

$\geq 35$
$<35$

$103(47.9)$

1

0.036

$<35$

$112(52)$

$1.52(1.03-2.27)$

Sex

$\begin{array}{lccc}\text { Female } & 99(46) & 1 & 0.033 \\ \text { Male } & 116(54) & 1.54(1.04-2.28) & \end{array}$

Occupation

$\begin{array}{lccc}\text { Daily Wagers } & 69(32) & 1 & 0.001 \\ \text { Others } & 146(67.9) & 2.0(1.33-3.01) & \end{array}$

Examination Time (In minutes) ${ }^{s}$
$\leq 3$
$110(52.1)$
1
$<0.001$
$>3$
$101(47.8)$
$2.39(1.57-3.64)$

Perception on Doctor's Expertise

Satisfactory /Poor

Very Good /Good

Perception on Doctor's Attitude
Satisfactory /Poor
Very Good /Good

35 (16.2)

$180(83.7)$

1

0.06

$32(14.8)$

183(85.1)

1

0.045

$1.68(1.01-2.79)$

Reason for opting PHC

Due to financial Reasons

Due to other Reasons

$$
52(25)
$$

$156(75)$
$1.690 .98-2.63)$

$1 \quad 0.002$

$1.95(1.27-3.0)$

(S-N=211, @- N=208 C.I - confidence Interval) 
Table-4 Factors associated with Perceived Quality of services Bivariate Analysis

\begin{tabular}{|c|c|c|c|}
\hline Respondent Characteristics & $\begin{array}{c}\text { Respondent } \\
\text { Perceived better } \\
\text { quality of services } \\
\mathrm{N}(\%) \\
(\mathrm{N}=196)\end{array}$ & $\begin{array}{c}\text { Odds Ratio (95\% } \\
\text { C.I.) }\end{array}$ & P value \\
\hline \multicolumn{4}{|l|}{ Age } \\
\hline 1. $\geq 35$ & $94(48)$ & 1 & 0.037 \\
\hline 2. $<35$ & $102(52)$ & $1.52(1.02-2.28)$ & \\
\hline \multicolumn{4}{|l|}{ Sex } \\
\hline 1. Female & $88(44.8)$ & 1 & 0.013 \\
\hline 2. Male & $108(55.1)$ & $1.66(1.11-2.47)$ & \\
\hline
\end{tabular}

Education
1. Illiterate
$45(22.9)$
1
$<0.001$
2. Literate
$151(77)$
$2.19(1.41-3.39)$
Examination Time (In minutes)
1. $\leq 3$
$102 @(52.8)$
1
$<0.001$
2. $>3$
$91(47.1)$
$2.18(1.43-3.32)$

(a)

Perception on Doctor's

Expertise

1. Satisfactory/Poor

$23(11.7)$

1

0.001

2. Very Good/Good

$173(88.2)$

$2.46(1.43-4.23)$

Perception on Doctor's

Attitude
1. Very Good/Good
$25(12.8)$
1
0.001
2. Satisfactory /Poor
$171(87.2)$
$0.41(0.24-0.69)$

(a) $-\mathrm{N}=193$ ) 
Page 18/20 
Table 5 Factors associated with client satisfaction and perceived better quality of services (PBQS) Multivariate Analysis

Client Satisfaction $(\mathrm{N}=215)$

Respondent Characteristics

N (\%) $\quad$ Adjusted O.R. P value

(95\% C.I.)

Sex

1. Female

$99(48.5)$

$1 \quad 0.024$

2. Male

$116(59.2) \quad 1.63(1.07-2.5)$

Occupation

1. Daily Wagers

$69(43.4)$

$1 \quad 0.001$

2. Others

$146(60.6) \quad 1.76(1.14-2.71)$

Examination Time (In

minutes $)^{\mathrm{s}}$

1. $\leq 3$

$110(45.3)$

$1<0.001$

2. $>3$

$101(66.4) \quad 2.24(1.44-3.5)$

Reason for opting PHC @

1. Due to financial

Reasons

$52(41.6)$

1

1

0.002

2. Due to other Reasons $\quad 156(58.2) \quad 1.95(1.27-3.0) \quad 2.07(1.32-3.27)$

(\$-N=211,@- N=208 C.I. -confidence interval )

Table 6 Factors associated with perceived better quality of services (PBQS) (N=196) Multivariate Analysis 
Sex

$\begin{array}{lrrr}\text { Female } & 88(44) & 1 & 0.048 \\ \text { Male } & 108(56.5) & 1.57(1.00-2.46) & \end{array}$

Education

$\begin{array}{lrrr}\text { Illiterate } & 45(36.9) & 1 & 0.011 \\ \text { Literate } & 151(56.1) & 1.87(1.16-3.02) & \end{array}$

Examination Time ${ }^{\#}$

$\begin{array}{llrl}\leq 3 \text { minutes } & 102(42.7) & 1 & \\ >3 \text { minutes } & 91(61.9) & 2.04(1.31-3.15) & 0.001\end{array}$

Perception on doctor's

attitude

Satisfactory/ poor

$25(32.9)$

$1 \quad 0.002$

Very good / good

$171(54.3) \quad 2.46(1.41-4.32)$

(\#- N=193, C.I. -confidence interval) 